\title{
Serm Sulfhydryl Levels and Rheumatoid Factors in Rheumatoid Arthritis
}

\author{
Shiro Kosaka \\ Institute of Balneology and Narugo Branch \\ of the University Hospital (Prof. T. Sugiyama), \\ Tohoku University School of Medicine, Sendai
}

\begin{abstract}
Serum total sulfhydryl level (SH-level) was determined in 285 cases of rheumatoid arthritis and other allied diseases and of healthy subjeots. The SH. level was within the normal limits in 28 of 33 cases of rheumatoid arthritis. However, it was slightly lower than that of the controls. The SH-level was subnormal in the remaining 5 cases. These 5 cases showed high titer of rheumatoid factors and an increase in the amount of IgM. The results suggest that the formation of macroglobulin, particularly that of rheumatoid factor is related to a decrease of SH-level. When L-cysteine was injected into the joint cavity of a patient, IgM disappeared temporarily from the synovial fluid at $30 \mathrm{~min}$ and $3 \mathrm{hr}$. Glutathione had not such an effect. Thus, different SH-compounds seem to exert different effects on the organism.
\end{abstract}

In a previous paper, the present author reported the dissociation of the rheumatoid factor in vivo, only when SH-compounds were injected into the joint. On the other hand, the administration of SH-compounds by other routes exerted influences neither on the rheumatoid factor of the patient nor on experimentally produced rheumatoid factor-like substance in rabbits. ${ }^{1}$

It seems probable that there is a close relationship between the serum SHlevel and macroglobulin, particularly the titer of rheumatoid factor. In the present communication the results are described of the determination of SHlevel in serum and synovial fluid from 285 cases of rheumatoid arthritis, other related diseases, miscellaneous non-rheumatic diseases and of healthy subjects. The relationships among rheumatoid factor, IgM and $\gamma$-globulin are also discussed.

Polarographic technic, ${ }^{2}$ spectrophotometric method [5,5'-dithiobis(2-nitrobenzoic acid) (DTNB), ${ }^{3,4}$ parachloromercuribenzoate (PCMB, more recently designated as $p$-hydroxymercuribenzoate) ${ }^{5}$ and $\mathrm{N}$-ethylmaleimide (NEM) ${ }^{6}$ ] have been applied to the determination of protein $\mathrm{SH}$-level in serum. The polarographic method had been frequently used. The spectrophotometric method by Ellman ${ }^{3}$ has been seldom employed for clinical use in spite of its simplicity. The difficulty of this method, when applied for human serum, is obviated by the present author.

Received for publication, December 25, 1969.

* Studies on the role of SH-compounds in rheumatoid arthritis, II. 


\section{Methods and Materials}

1) Determination of serum $\mathrm{SH}$-level

A use was made of a reagent of DTNB $(39.6 \mathrm{mg})$ dissolved in $10 \mathrm{ml}$ of a phosphate buffer solution $(\mu=0.1, \mathrm{pH}=7.0)$. To $3.0 \mathrm{ml}$ of a mixture of $0.3 \mathrm{ml}$ of sample serum, 2.0 $\mathrm{ml}$ of phosphate buffer $(\mu=0.1, \mathrm{pH}=8.0)$ and $5.0 \mathrm{ml}$ of water, $0.02 \mathrm{ml}$ of the DTNB reagent was added. The resulting mixture was kept at room temperature for $2 \mathrm{hr}$.

Absorbanoe read at $412 \mathrm{~m} \mu$ with a spectrophotometer (Hitachi, Model FPU-2A) was converted to $\mathrm{mM}$ of $\mathrm{SH}$ based on the following formula.

$$
\mathrm{Co}=\frac{\mathrm{A}}{\varepsilon} \mathrm{D}
$$

Co $=$ original concentration

$\mathrm{A}=$ absorbance at $412 \mathrm{~m} \mu$

$\varepsilon=$ extinction coefficient

$=13,600 / \mathrm{M} / \mathrm{cm}$

$\mathrm{D}=$ dilution factor

All the serum samples were used within $12 \mathrm{hr}$ after the blood was taken.

\section{2) Determination of rheumatoid factor}

RA test and hemagglutination test were used for the investigation of rheumatoid factor. In hemagglutination test, a use was made of a modification by Heller et al. ${ }^{7}$ of the Waller-Rose reaction. In the RA test, a kit from Hyland laboratories was used.

The results of RA tests were evaluated acoording to the following 4 oategories.

Strong agglutination within $1 \mathrm{~min} \quad$ H

Agglutination within $1 \mathrm{~min}$

Agglutination within $3 \mathrm{~min}$

No agglutination even after $3 \mathrm{~min}$

\section{3) Quantification of serum IgM}

Immunodiffusion plates containing antiserum to human $\gamma \mathrm{M}$ immunoglobulin in agar from Hyland laboratories were used for the quantification of serum IgM. The diameter of a precipitin ring formed for human serum and for synovial fluid was each determined by the single radial immunodiffusion method. The IgM content was calculated in reference to a straight line of the best fit drawn on the basis of experimental data.

\section{RESULTS}

\section{1) Serum SH-levels in normal adults}

Serum samples were taken from 78 males between the age of 20 and 30 and from 55 females between the ages of 20 and 25 . The serum SH-levels of these cases were in the range between 0.286 and $0.582 \mathrm{mM} / 1$. The level seems to represent the normal range. On the average, it was $0.414 \mathrm{mM} / 1$ for male and 0.427 $\mathrm{mM} / 1$ for female. Thus the average value for the females seems to be somewhat higher than that for the males. No case with an SH-level below $0.362 \mathrm{mM} / 1$ was found in females (Fig. 1).

Then an attempt was made to assess the reliability of the method of Ellman in which the DTNB reagent was used and the result was calculated with a formula. 
A satisfactory reference diagram was obtained between the optical density and the concentration of cysteine over a wide range (Fig. 2).

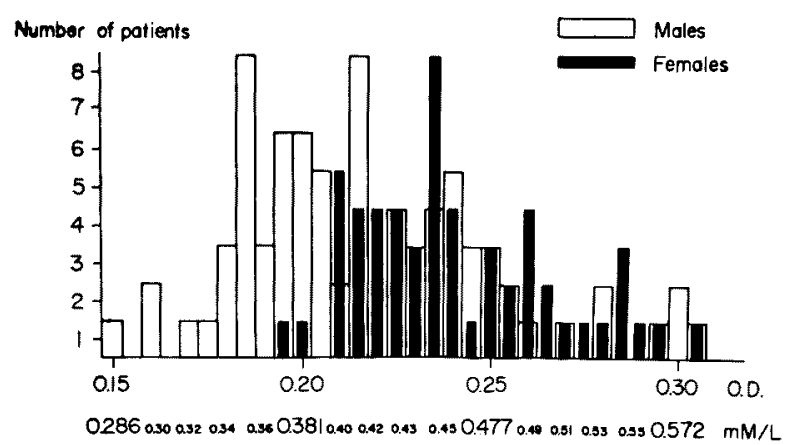

Fig. 1. Serum sulfhydryl levels in normal adults.

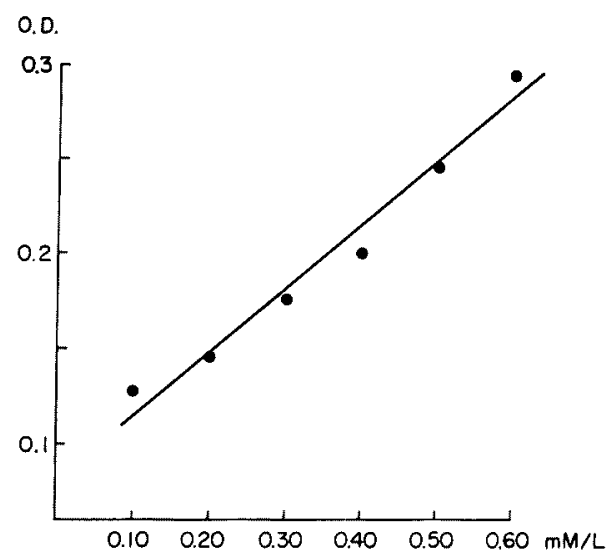

Fig. 2. Demonstration of linear relationship in determination of sulfhydryl groups with L-cysteine.

2) Serum SH-levels in rheumatoid arthritis

In 28 of 33 cases with classical and definite rheumatoid arthritis, the SH-levels were within the normal limits. However, the level was always below $0.40 \mathrm{mM} / 1$ : In most of the above 28 cases, it was between 0.30 and $0.35 \mathrm{mM} / 1$. In the remaining 5 , the SH-level was below the normal range, the minimal level being $0.13 \mathrm{mM} / 1$ (Fig. 3).

3) A relationship between the $S H$-level and the titer of rheumatoid factor determined by the Waaler-Rose reaction and $R A$-test

No definite correlation was found between SH-level and Waaler-Rose reaction when SH-level was within normal limits. However, in 5 cases with subnormal SH- 
levels, hemagglutinin titer was 1:448 to 1:3,584 (Fig. 4). A study of the relationship between RA-test and SH-level ( 5 cases, RA-test strongly positive) revealed similar results (Fig. 5).

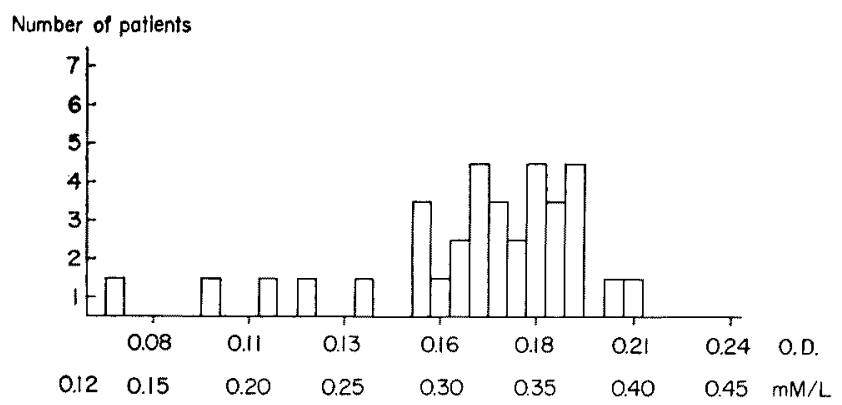

Fig. 3. Serum sulfhydryl levels in rheumatoid arthritis.

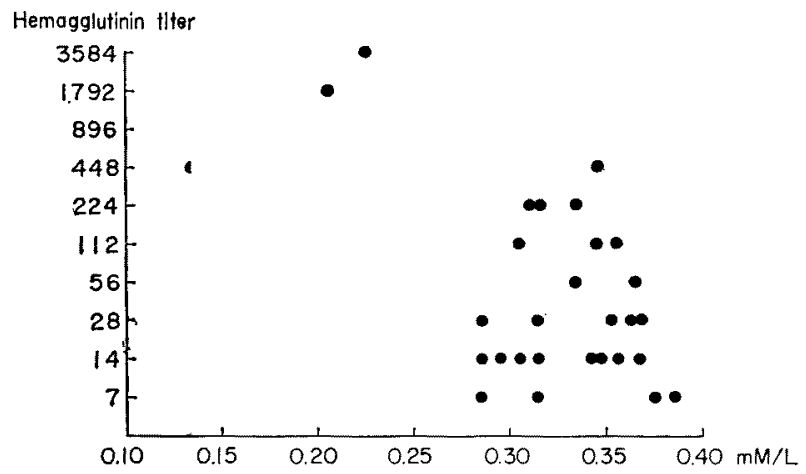

Fig. 4. Correlation of serum sulfhydryl levels with henag. glutinin titers.

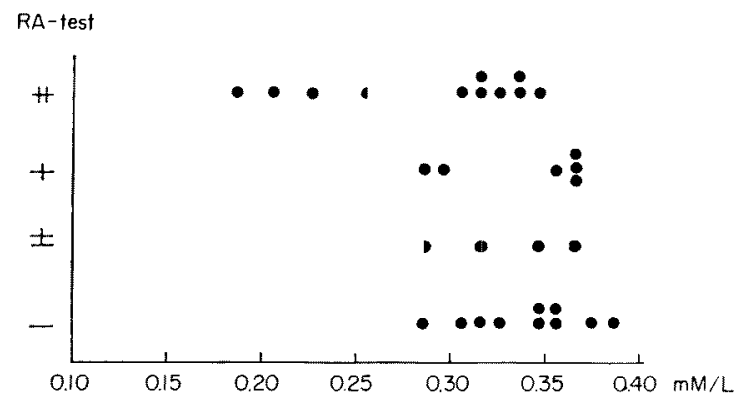

Fig. 5. Correlation of serum sulfhydryl levels with RA-test. 
4) A relationship between the serum $S H$-level and the concentration of serum IgM in patients with rheumatoid arthritis

The quantity of IgM was almost within normal limits in agreement with the study of other investigators. ${ }^{8}$ In most of the cases, the quantity of IgM was at a level of 60 to $100 \mathrm{mg} / 100 \mathrm{ml}$. Of the 5 cases with subnormal SH-levels, it was $117 \mathrm{mg} / 100 \mathrm{ml}$ in $3,113 \mathrm{mg} / 100 \mathrm{ml}$ in a case and $97 \mathrm{mg} / 100 \mathrm{ml}$ in another. The result indicates an elevation in the quantity of $\mathrm{IgM}$ in general. However, there was no definite relationship between the quantity of IgM and the serum SH-level in the remaining 28 cases (Fig. 6). Electrophoretic studies did not reveal any relationship between the value of $\gamma$-globulin level (\%) and the serum SH-level (Fig. 7).

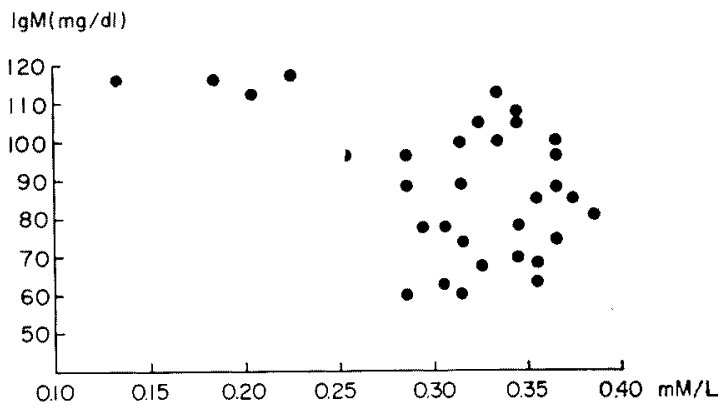

Fig. 6. Correlation of serum sulfhydryl levels with serum IgM concentrations.

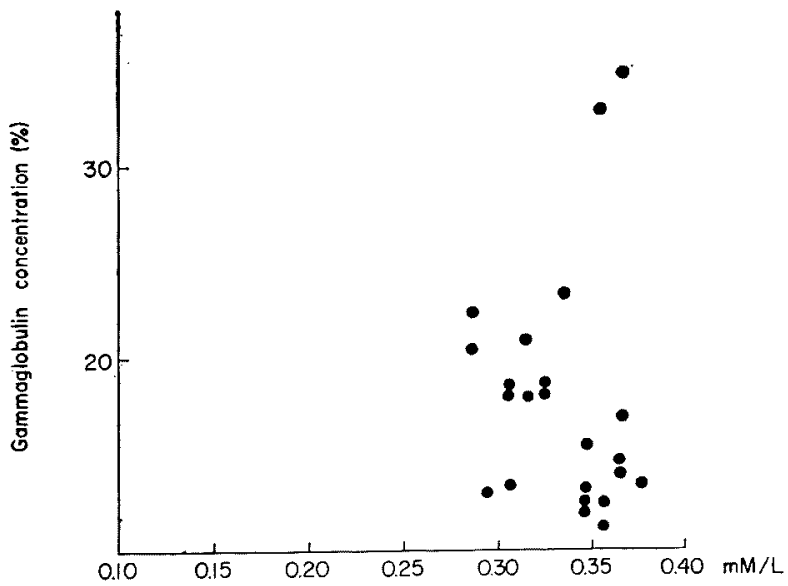

Fig. 7. Correlation of serum sulfhydryl levels with serum gammaglobulin.

5) A change in serum $S H$-level after an in vivo injection of $S H$-compounds

One thousand $\mathrm{mg}$ each of L-cysteine and glutathione were injected to healthy human subjects by an intravenous route. The serum $\mathrm{SH}$-level was determined 
at intervals for $2 \mathrm{hr}$. There was a slight increase for $10 \mathrm{~min}$ of the serum SH-level only after the injection of L-cysteine. As a whole, remarkable changes were not observed (Fig. 8).

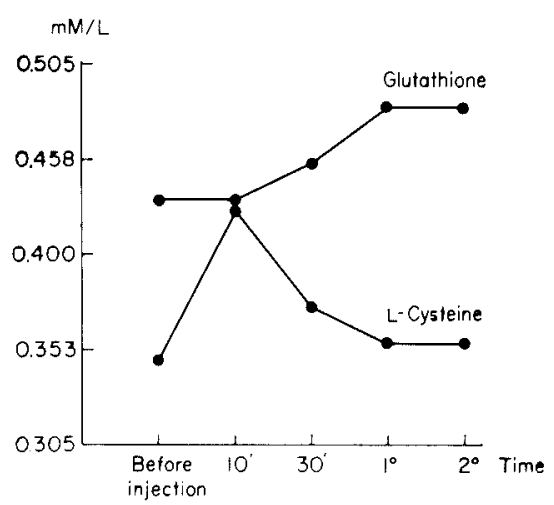

Fig. 8. Serial serum sulfhydryl determination following intravenous injection of $\mathrm{SH}$-compounds.

6) Correlation of SH-levels with IgM and rheumatoid factor in synovial fluid following intraarticular injection of $S H$-compounds

When L-cysteine was injected into the joint of a patient with rheumatoid arthritis, a rapid elevation of the $\mathrm{SH}$-level in the synovial fluid was observed at $30 \mathrm{~min}$ and $3 \mathrm{hr}$ after the injection, associated with the disappearance of IgM. As reported previously by the present author, there was a fall in the agglutinin titer, as determined by the Waaler-Rose test, after L-cysteine injection. Also there was a tendency that RA-tests became negative. In the present experiment, when glutathione was injected, there was a rise in SH-level, whereas the quantity of IgM and titer of rheumatoid factor remained at the same level. These results are in agreement with those of $\mathrm{Jaffe}^{9}$ and may possibly be ascribed to weak in vitro dissociation of rheumatoid factor (Table 1).

\section{7) SH-level in various diseases other than rheumatoid arthritis}

The SH-level in 32 cases of rheumatic diseases other than rheumatoid arthritis was all within normal limits. A tendency was observed that the SH-level was low in cases of systemic lupus erythematosus (Fig. 9).

Of the 87 cases of non-rheumatic diseases, there was a marked fall in SHlevel in 8 cases of nephrotic syndrome and chronic nephritis: the SH-level was below normal in 6 of the above 8 cases. Particularly in 2 of these 6 cases, it was as low as $0.162 \mathrm{mM} / 1$ and $0.143 \mathrm{mM} / 1$. Next to the above diseases, cases of cancer showed a somewhat low SH-level. In 6 of 20 cancer-cases it was below normal. In the remaining 14 cases, it was within normal limits, but showed a tendency to low SH-levels (Fig. 10). 
TABLE 1. Correlation of sulfhydryl levels with IgM and rheumatoid factor in synovial fluid following intraarticular injection of $\mathbf{S H}$-compounds

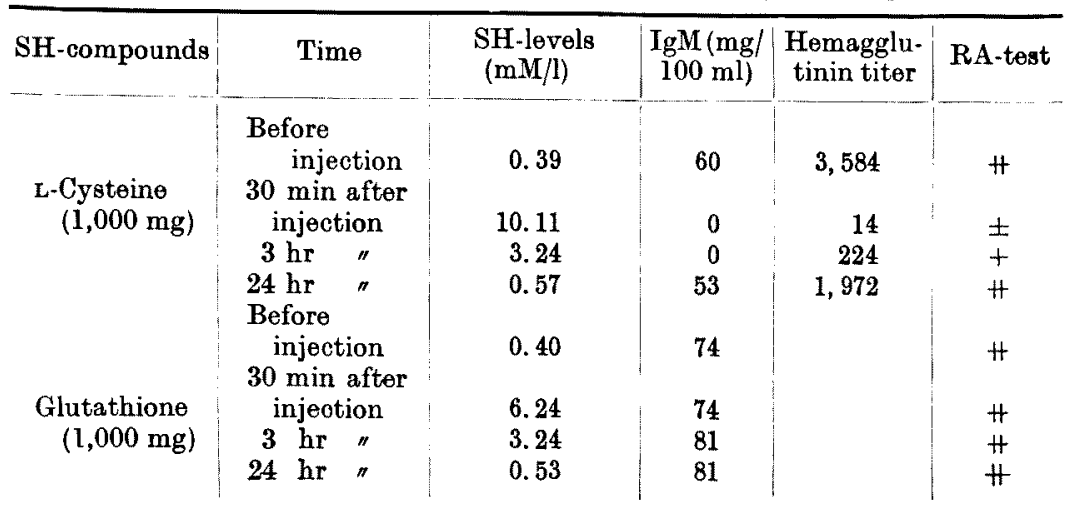

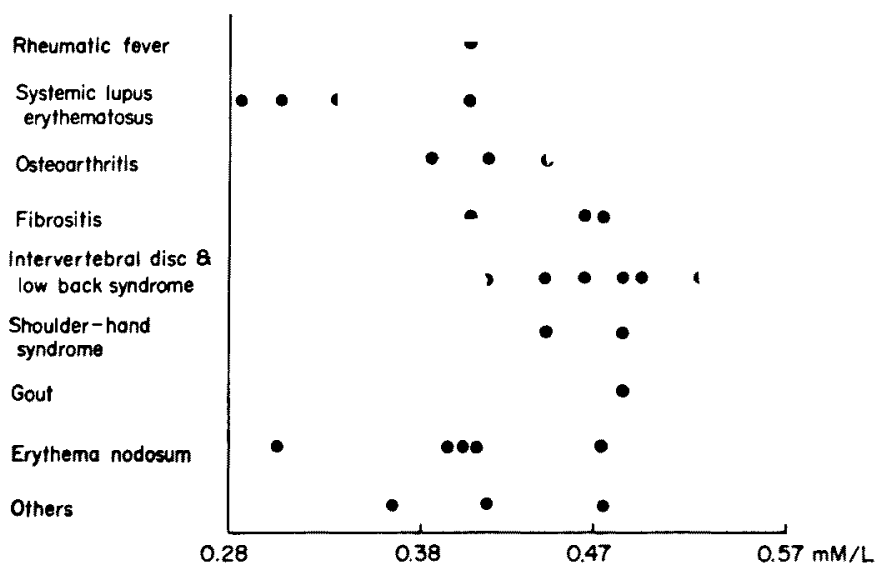

Fig. 9. Serum sulfhydryl levels in other rheumatic diseases.

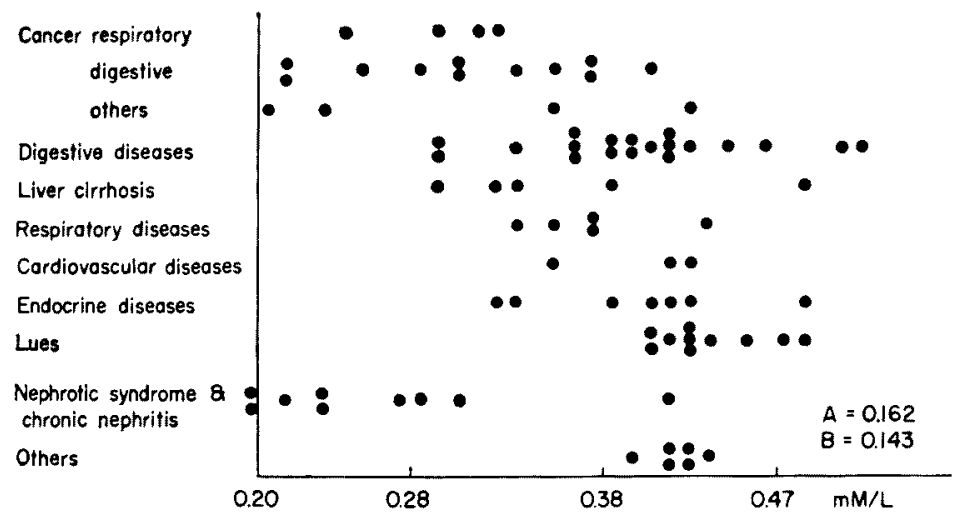

Fig. 10. Serum sulfhydryl levels in other miscellaneous diseases. 


\section{Discussion}

It was demonstrated in the present experiments that serum SH-level decreased in patients with rheumatoid arthritis. According to Lorber et al., ${ }^{\mathbf{1 0}}$ the serum SH-content was abnormally low in patients with rheumatoid arthritis. They stated that the deficiency in SH-groups of protein may be responsible for the formation of abnormal immunoglobulin including rheumatoid factor. Namely the low SH-levels occur in conjunction with the appearance of abnormal 19-S macroglobulin (for example, rheumatoid factor). A decrease in SH-level can be induced in serum by in vitro oxidation or by heating which leads to mild protein denaturation. ${ }^{11-13}$ Such denaturation could proceed spontaneously, when the reactions of in vivo reduction of disulfide bonds are impaired. When spontaneous formation of disulfide bonds increases, the formation of macroglobulin is facilitated. Lorber et al. have proposed a model to explain such a result.

The rheumatoid factor, which is contained principally in IgM, belongs to 19-S macroglobulin. The present author's study indicates that in the cases showing abnormally low serum SH-content, the hemagglutination of Waaler-Rose reaction and RA-test were strongly positive and that there was a rise in the quantity of IgM. This finding supports the hypothesis of Lorber et $a l .^{10}$

Also a decrease in serum $\mathrm{SH}$-level in rheumatoid arthritis with vasculitis and in lupus erythematosus was reported by Lorber et $a l .{ }^{10} \quad \mathrm{~A}$ similar decrease in serum SH-level was found by the present author in lupus erythematosus, which might be ascribed to concomitant vasculitis. Schoenbach et al. ${ }^{14}$ determined by amperometric titration the SH-level in cases of malignant tumors, multiple myeloma, lupus erythematosus and other miscellaneous diseases, and found a marked lowering in serum SH-level. According to their results, the serum SH-level was low in the cases of malignant tumor in agreement with the results of the present author. It is further interesting that the SH-level was low in the cases of nephrotic syndrome and chronic nephritis. In nephrotic syndrome, there was an increase of $\alpha_{2}$-macroglobulin. However, the relationship between an increase of $\alpha_{2}$-macroglobulin and a lowering of $\mathrm{SH}$-level requires further investigation.

As described above, the serum SH-level was low in patients with rheumatoid arthritis. Thus attempts have been made to improve clinical symptoms and to achieve a fall in rheumatoid factor activity by the administration of SHcompounds to the patients. $\mathrm{Jaffe}^{15}$ observed the effects of plasmapheresis and those of administration of $2 \mathrm{~g} /$ day of penicillamine on the level of circulating rheumatoid factor. Both methods brought about a fall in the level of rheumatoid factor. The fall was prompt and transient after plasmapheresis but more lasting after the administration of penicillamine. Although the evaluation of the clinical effects by the administration of penicillamine was difficult, Jaffe reported the impression that there was a gradual improvement in the objective signs and subjective symptoms. Jaffe ${ }^{16}$ observed an improvement in the clinical symptoms and a significant fall in the level of rheumatoid factor, when penicillamine was administered to a patient with rheumatoid arthritis accompanied by 
neuropathy with chronic leg ulcers and arteritis, who showed a high titer of rheumatoid factor. Lorber ${ }^{17}$ administered to three patients with rheumatoid lung diseases $50 \mathrm{mg} /$ day of pyridoxine, 1 to $3 \mathrm{~g} /$ day of d-penicillamine and observed then at biweekly intervals for the period of 14 months. In these patients, relief of pain, stiffness and shortness of breath was observed within 4 weeks. Together with a decrease in the titer of rheumatoid factor, there was also an increase in serum protein SH-level in these patients.

In addition to the clinical observations, experimental immuno-suppresive effects by penicillamine have been reported as well. Altman and Tobin ${ }^{18}$ observed a suppression of the immune response in the rabbits which had received dl-penicillamine before the intravenous injection of ${ }^{131}$ I-labeled human serum albumin. When an antigen was injected to mice after 3 weeks of administration of dl-penicillamine, there was an overall reduction in antibody formation (Hübner and Gengozian $^{19}$ ).

As described above, there have been several experimental and clinical reports which indicate the in vivo changes resulting from administration of dl-penicillamine. It is quite probable that penicillamine exerts specific effects somewhat different from those of other SH-compounds. The oral administration of L-cysteine as reported in the previous communication caused no remarkable change in the titer of rheumatoid factor and in clinical symptoms. These results may be related to the difference in specificity between penicillamine and other SH-compounds. Also a decrease in IgM level in the joint cavity was observed only by the injection of cysteine, but not by that of glutathione. Therefore, it seems likely that there is a difference among various SH-compounds in their effects on organisms. Especially, the reduction in the titer of rheumatoid factor as a result of the administration of penicillamine may be related not only to the dissociation, but also to the reactivity of the penicillamine molecule or its specific chelating properties. ${ }^{20}$

\section{References}

1) Kosaka, S. Effects of SH-compounds on rheumatoid factors in rheumatoid arthritis. Tohoku J. exp. Med., 1969, 97, 233-243.

2) Benesch, R.E., Lardy, H.A. \& Benesch, R. The sulfhydryl groups of crystalline proteins. I. Some albumins, enzymes, and hemoglobins. J. biol. Chem., 1955, 216 , $663-676$.

3) Ellman, G.L. Tissue sulfhydryl groups. Arch. Biochem., 1959, 82, 70-77.

4) Beutler, E., Duron, O. \& Kelly, B.M. Improved method for the determination of blood glutathione. J. Lab. clin. Med., 1963, 61, 882-888.

5) Isles, T.E. \& Jocelyn, P.C. The reaction of protein thiol groups with some disulphides. Biochem. $J ., 1963,88,84-88$.

6) Morell, S.A., Ayers, V.E., Greenwalt, T.J. \& Hoffman, P. Thiols of the erythrocyte. I. Reaction of N-ethyl maleimide with intact erythrocytes. J. biol. Chem., 1964, 239, 2696- 2705.

7) Heller, G., Jacobson, A.S. \& Kololdny, M.H. A modification of the hemagglutination test for rheumatoid arthritis. Proc. Soc. exp. Biol. Med., 1949, 72, 316-323.

8) Schultze, H.E. \& Heremans, J.F. Molecular Biology of Human Proteins with Special Reference to Plasma Proteins. Elsevier Publishing Co., Amsterdam-London-New York, 1966, vol. 1, p. 224. 
9) Jaffe, I.A. Intra-articular dissociation of the rheumatoid factor. J. Lab. clin. Med., 1962, 60, 409-421.

10) Lorber, A., Pearson, C.M., Meredith, W.L. \& Gatz-Mandell, L.E. Serum sulfhydryl determinations and significance in connective tissue diseases. Ann. intern. Med., 1964, 61, 423-434.

1I) Jandl, J.H., Engle, L.K. \& Allen, D.W. Oxidative hemolysis and precipitation of hemoglobin. I. Heinz body anemias as an acceleration of red cell aging. $J$. clin. Invest., 1960, 39, 1818-1836.

12) Steinauf, L.K. \& Dandliker, W.B. A study of the reaction of the disulfide groups of bovine serum albumin during heat denaturation. J. Amer. chem. Soc., 1958, 80, 3833-3835.

13) Lorber, A. Increased globulin fractionation by an improved vertical gel electrophoretic technique. J. Lab. clin. Med., 1964, 64, 133-144.

14) Schoenbach, E.B., Weissman, N. \& Armistead, E.B. The determination of sulfhydryl groups in serum. II. Protein alterations associated with disease. J. clin. Invest., $1951,30,762-777$.

15) Jaffe, I.A. Comparison of the effect of plasmapheresis and penicillamine on the level of circulating rheumatoid factor. Ann. rheum. Dis., 1963, 22, 71-76.

16) Jaffe, I.A. Rheumatoid arthritis with arteritis. Report of a case treated with penicillamine. Ann. intern. Med., 1964, 61, 556-563.

17) Lorber, A. Penicillamine therapy for rheumatoid lung disease: Effects on protein sulphydryl groups. Nature, 1966, 210, 1235-1237.

18) Altman, K. \& Tobin, M.S. Suppression of the primary immune response induced by D-L penicillamine. Proc. Soc. exp. Biol. Med., 1965, 118, 554-557.

19) Hübner, K.F. \& Gengozian, N. Depression of the primary immune response by dlpenicillamine. Proc. Soc. exp. Biol. Med., 1965, 118, 561-565.

20) Jaffe, I.A. \& Merryman, P. Effect of increased serum sulphydryl content on titre of rheumatoid factor. Ann. theum. Dis., 1968, 27, 14-18. 